\title{
THE SEARCH FOR THE SITE OF VISUAL ADAPTATION
}

\author{
DANIEL G. GreEN \\ University of Michigan, Ann Arbor, MI 48109, U.S.A.
}

It was almost exactly 25 years ago as a graduate student in Electrical Engineering that my own intellectual curosity about mechanisms of visual adaptation was kindled. Adaptation is one of the most profound and pervasive sensory phenomena. After steady exposure to a sensory stimulus, sensitivity is almost always decreased. Odors become less noticeable, lights appear dimmer, tastes become less strong and so on. Consequently its study is both interesting and important.

It would be nice to say that my own interest stems from recognizing this, but somehow it didn't happen like that. In fact the influence of people rather than ideas was most important. The journal (and I) began vision research in the middle of what I think of as the Rushton era. William A. H. Rushton was a brilliant, dynamic individual who made monumental contributions and for a time gave direction to much of our thinking and research on visual adaptation. It was hearing a lecture by W.A.H.R. himself in the fall of 1960 that served to channel my own interests toward the study of the visual system. Christina Enroth-Cugell had invited Rushton to deliver a lecture to the Biomedical Engineering group at Northwestern University in Evanston. As I recollect it, the lecture was an animated and forceful discourse on visual adaptation, covering much the same material published later that academic year in a paper titled, "The Intensity Factor in Vision" (Rushton, 1961a).

What I recall most vividly was Rushton's vigorous attack of the pigment depletion explanation for the changes in sensitivity which occur when the eye adapts to light or darkness. The focus of his assualt was Selig Hecht's simple and elegant photochemical ideas (Hecht, 1924).

* Rushton started out by setting the audience a problem, having to do with the minimum of balance weightings necessary to find the one heavier penny in a group of otherwise identical pennies. Only after someone could provide the answer were we privileged to receive his lecture.
Hecht's hypothesis was swept away by a series of experiments which directly measured the variables in question. Rushton had designed and built an instrument, the retinal densitometer, for objectively measuring pigment concentration in the living human eye (Campbell and Rushton, 1955). Measurements of the regeneration of visual pigment after exposure to a bright light were correlated with the recovery of an observer's ability to detect a dim stimulus. From these data, at every instant of time in the dark, the relationship between the concentration of visual pigment and psychophysically determined visual threshold could be inferred. Rather than the proportional relationship required by the photochemical theory of Hecht, the correct law, or so Rushton argued, was

$$
I_{\mathrm{D}}=I_{0} \mathrm{e}^{40(1-p)}
$$

where $I_{0}$ is the fully dark adapted threshold and $p$ is the proportion of rod pigment present (Rushton, 1961b). While, as I remember, I was rather put off by the ostentatious* style of the lecture as much designed to demonstrate brilliance as to inform-obviously science was making great progress. It was exciting to think we were beginning to understand the details of the machinery that determines why things appear as they do. To a young aspiring biomedical engineer the incisiveness of his analysis, the elegance of the opto-electric instrumentation, and the ability to infer a fundamental biological law were inspiring. Here was a man to be emulated-if one dared.

At the time, my own interests were in physiological control systems. As a graduate student in electrical engineering I was inclined to believe that engineers, who supposedly knew a lot about analyzing and modelling complex physical systems, could, using their tools of trade, make substantial contributions to understanding human regulatory processes. It was a point of view which in retrospect seems largely fallacious on several grounds, the most important one being that it was based on the incorrect assumption that biologists and physi- 
ologists were incapable of taking such an approach. Rushton's lecture provided ample evidence that there was at least one physiologist whose abilities to handle mathematics and quantitative methods were much better than my own. It is hard to know what impact that discovery had. In fact, it took five years for my interests in adaptation to mature. During that time I had the opportunity to get to know Fergus Campbell and later to get postdoctoral training with him in the Physiological Laboratory in Cambridge, where not only Rushton but nearly everyone was much more mathematically able than I. While this served to put my abilities into perspcctive it was the influence of a number of key individuals, namely Christina EnrothCugell, Fergus Campbell, John Robson and Mathew Alpern, that was most strongly felt. One thing I learned was that science moves forward using mathematics and other tools, but what is most important is the process of formulating hypothesis and then designing crucial experiments to test them.

\section{Adaptation pools}

Before continuing further, I would like to consider the question of what is a reasonable operational definition of adaptation. I repeatedly discover how muddled my own thinking is about this and so possibly some attempt to be more precise will be of mutual benefit. In general we are referring to the situation where the presence of one light (the adapting light) reduces the size of the response evoked by a second test light. We use the term "light adaptation" if the two lights are presented simultaneously and the term "dark adaptation" for the persistent aftereffect of having previously presented an adapting light. Words such as accommodation, inhibition, habituation, fatigue and masking are also used to describe competitive interactions between stimuli. Are all such interactions also adaptation? I think not. It seems useful to restrict the term adaptation to those phenomena where the adapting light and the test stimulus both produce the same primary effect. At the level of retinal ganglion cells, for example, adaptation and inhibition are not the same. By adaptation we mean not only that when a test probe is coupled with an adapting background it evokes a smaller response, but also that adapting and test lights, when individually presented, elicit responses of the same sign. This is in sharp contrast to inhibition where if one of the two stimuli evokes a response of one sign then the other stimulus by itself evokes a response of the opposite sign. Thus, I would like to restrict adaptation to those effects which are multiplicative rather than subtractive (Adelson, 1982).

Returning to our state of knowledge 25 years ago, the really fascinating thing about Rushton's work was that it pointed to so many interesting questions remaining to be answered. The relationship between rod threshold and the instantaneous level of rhodopsin was still a puzzle. Why did bleaching a very small amount of rhodopsin have such a devastating ability to elevate visual threshold? As Rushton was quick to point out, it was not, as George Wald (1954) had suggested, that bleaching a few molecules of rhodopsin could profoundly affect the photoreceptor's ability to respond to light. In fact the changes in sensitivity occurring during light and dark adaptation did not appear to originate in the photoreceptors themselves. Leo Lipetz (1961), working with isolated frog retina, had found that the desensitizing effects of light can spread laterally across the retina. While important controls for scattered light were lacking in Lipetz's experiments, the significant aspect of his findings, that illumination (or bleaching) in one area of the retina could depress the sensitivity of other remote areas, was later confirmed and extended by the work coming from several other laboratories including my own (Rushton and Westheimer, 1962; Rushton, 1965b; Barlow and Andrews, 1967; Easter, 1968; Cleland and Enroth-Cugell, 1968; Enroth-Cugell and Shapley, 1973; Green et al., 1977; Cicerone and Green, 1980). Rushton introduced the concept of an "adaptation pool" to explain the fact that changes in sensitivity seemed to be produced by signals summed from many receptors. The logic of the inference is illustrated in Fig. 1. If a test stimulus falling on one set of receptors can be affected by an adapting light falling on another group of receptors, then the site of adaptation must be elsewhere than the photoreceptor. Moreover, Rushton reported that the threshold was the same irrespective of whether the adapting light fell on those receptors illuminated by the test or on the near neighbors. From this Rushton (1965a) concluded, "It is plain that adaptation of the rods is irrelevant, the adaptation of the pool is everything".

At the same time, the path that progress would take seemed straightforward and clear; detailed physiological experiments would pro- 
ARF

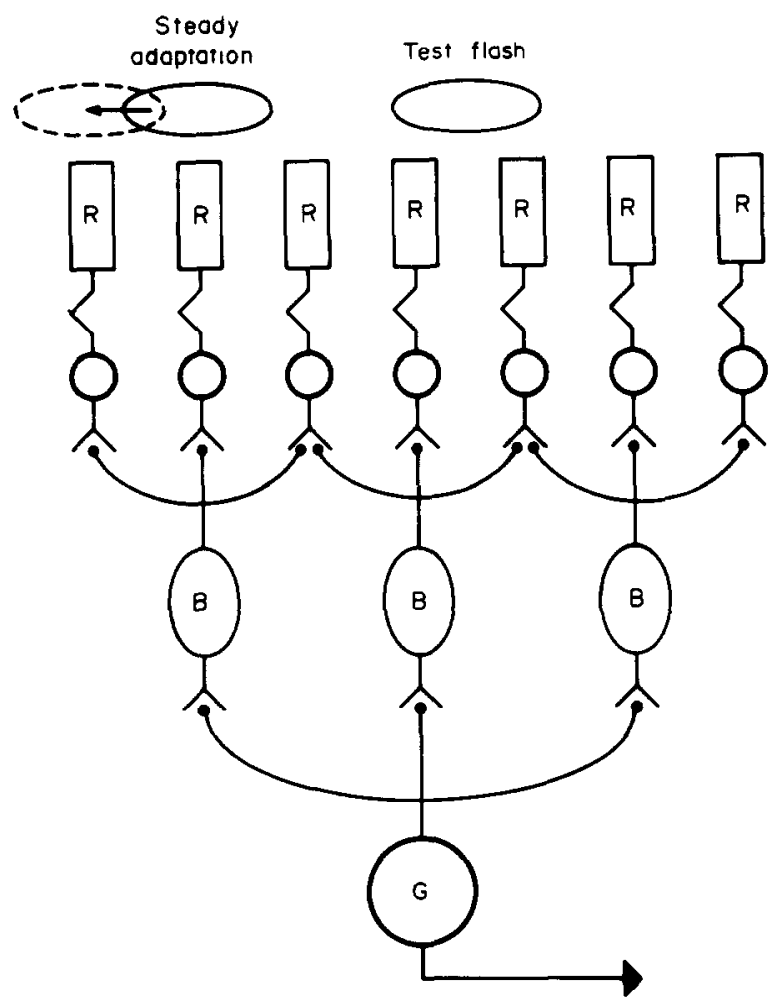

Fig. 1. Schematic diagram of retina indicating the logic behind pooling experiments. Assume that one is measuring the responses of a ganglion cell (G) to a flash of light. If the adapting stimulus which falls on one group of receptors can affect the response to a test stimulus which stimulates another separate set of receptors then the site of adaptation cannot be in the receptors themselves.

vide an understanding of the organization of the pool, and the problem would be solved.

Needless to say, things did not turn out as expected. Ahead lay complexities and surprises no one would have dreamt existed. It seems only right to add that not only was I wrong about what the future held, but I really didn't have a good perspective on the past. I tended to give Rushton credit for discovering things which in retrospect were apparent to earlier investigators. Even Hecht (1934) himself seemed aware of the need to postulate the log relationship in equation (1). In 1940 Lythgoe wrote a paper on the mechanisms of dark adaptation that contains a detailed discussion of the difficulties in accepting a purely photochemical explanation for the phenomena of dark adaptation. Granit et al. (1938) and Granit et al. (1939) had shown large changes in the $b$-wave of the ERG without correspondingly large changes in rhodopsin concentration. Schouten and Ornstein's (1939) measurements on the effect on sensitivity of nearby sources of light (glare) had shown that adaptation

"cannot possibly be photochemical in origin, both because it takes effect so quickly and because the effect is exercised at a distance"

(Lythgoe, 1940).

\section{Receptor adaptation}

We had all accepted the validity of Rushton's conclusion that a finding of adaptation exercised at a distance made any theory of visual adaptation which invoked receptor adaptation untenable. Consequently the array of experimental findings which appeared beginning in the early 1970 s was a great surprise. Using the late receptor potential of the monkey fovea, Boynton and Whitten (1970) showed that a steady background could desensitize primate cones. Dowling and Ripps' (1970, 1971, 1972) recordings from horizontal cells in the skate retina showed the adaptation was occurring at an early stage of retinal processing. Experiments in a variety of cold-blooded vertebrates using sodium aspartate to isolate receptor potentials provided evidence that photoreceptors displayed the full range of adaptive phenomena (Dowling and Ripps, 1972; Witkovsky et al., 1973; Hood and Hock, 1973; Normann and Werblin, 1974). Intracellular recordings from single photoreceptors showed directly that receptors themselves can significantly regulate their visual sensitivity (Grabowsky et al., 1972; Baylor and Hodgkin, 1974; Kleinschmidt and Dowling, 1975; Fain, 1976).

The above findings seemed to be completely at odds with the earlier evidence for adaptation pools. Pooling had been taken to imply that the site of adaptation was proximal to photoreceptors and yet direct recording showed that it was not.

A letter I received from John Dowling in November of 1971 captures this very well. It is a response to my inquiry about the possibility of doing a sabbatical in his laboratory.

I have thought some about what might be a fun thing for someone with your interests and talents to do in our lab and have the following idea, which may or may not interest you. As you heard last year in my seminar at Ann Arbor on S-potentials, I now believe that most of the sensitivity changes that occur in the skate retina during light and dark adaptation originate in the receptors. This view, of 
course, is hard to reconcile with the adaptation pool concept. This past summer we looked at receptor adaptation in skate, and these experiments confirmed and extended our view that sensitivity changes in dark and light adaptation are originating in the receptors. Thus, at the moment I am very confused about adaptation pools, lateral adaptive effects, etc. Thus I think the time is ripe for looking at lateral adaptive effects throughout the retina, beginning at the receptor and ending at the ganglion cell. We have the techniques now to do this and perhaps such a study would clear up the confusion. Does this strike your fancy?

I replied that, "The problem you suggest, in addition to being of great personal interest, is very close in spirit to the research I proposed in my current grant application", and went on to indicate my interest in spending a sabbatical year working with him.

What made the collaboration particularly interesting was the fact that my biases were quite different from John's. Working here in Ann Arbor, Lillian Tong and I had completed a set of experiments on adaptation pools in the rat ganglion cells (later published as Tong and Green, 1977). These experiments (see Fig. 2) convinced us that adaptation was pooled, but over subareas of the ganglion cell receptive field. We thought that this demonstrated electrophysiologically that sensitivity in mammalian rod systems was not regulated in the rod photoreceptors themselves. Consistent with this view were the earlier experiments on cat retinal ganglion cells of Cleland and Enroth-Cugell (1968) which showed that adaptation pools were about the same size as the ordinary receptive field center.

\section{Mechanism of adaptation}

At the heart of all this is a question about the site of action. Before I turn to the current state of knowledge (confusion?) with regard to these issues, I would like to consider intensityresponse functions.

Adaptation almost always does more than just reduce response amplitudes. The kinetics of the response are also affected. If one ignores these changes, one approach to adaptation is to ask how the presence of a background affects the stimulus-response relationships. The curve relating the peak response of a cell in the visual system to stimulus intensity (the intensity-

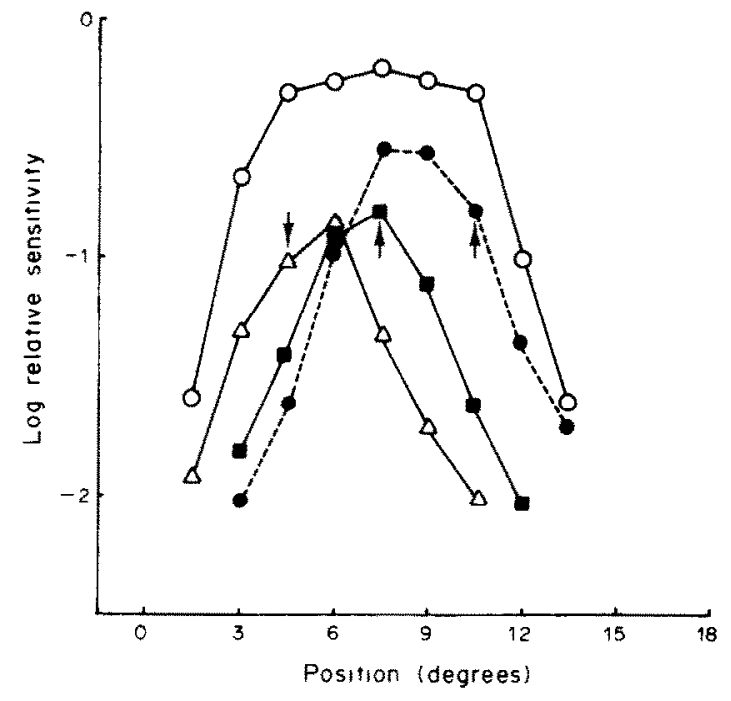

Fig. 2. Excitation receptive field (ERF) (O) and three adaptation receptive fields (ARFs) for a single optic rat tract fiber. For the ERF, the vertical axis gives for each position, along a line passing through the center, the reciprocal of the threshold for exciting the ganglion with a small test spot. With the ARFs the vertical axis gives the reciprocal of the intensity of an adapting spot required to bring a $\times 10$ threshold test spot (at the position of the arrow) to threshold. ARFs are for tests positioned $4.5^{\circ}(\triangle), 7.5^{\circ}(\mathrm{a})$, and $10.5^{\circ}(O)$ indicated by arrows. For tests at $4.5^{\circ}$ and $10.5^{\circ}$ the adaptating spot is most effective not at the site of the test but rather when displaced toward the center of the field. Also, note that all ARFs are narrower than the ERF. (From Tong and Green, 1977.)

response function) is frequently plotted on double or single logarithmic scales. Figure 3, for example, shows how backgrounds affect the response across levels of retinal processing in the rat. In general a background has two effects: (1) it reduces maximum response amplitude and (2) it causes the curves to shift laterally along the intensity axis. In analyzing such data it is useful to distinguish the reductions in response due to response ceilings (responsive compression) from those which involve actual changes in the properties of the retina (changes in gain) (Shapley and Enroth-Cugell, 1983).

\section{A response compression model}

First let us consider what should happen if response compression were the only mechanism affecting retinal sensitivity. With response compression we assume there is a fixed invariant relationship between the stimulus and its response. That is

$$
R=f(I)=f\left(I_{\mathrm{B}}+I_{\mathrm{i}}\right)
$$

where $I_{\mathrm{B}}$ is the background and $I_{\mathrm{t}}$ is the test stimulus. The effect of a steady background is to 


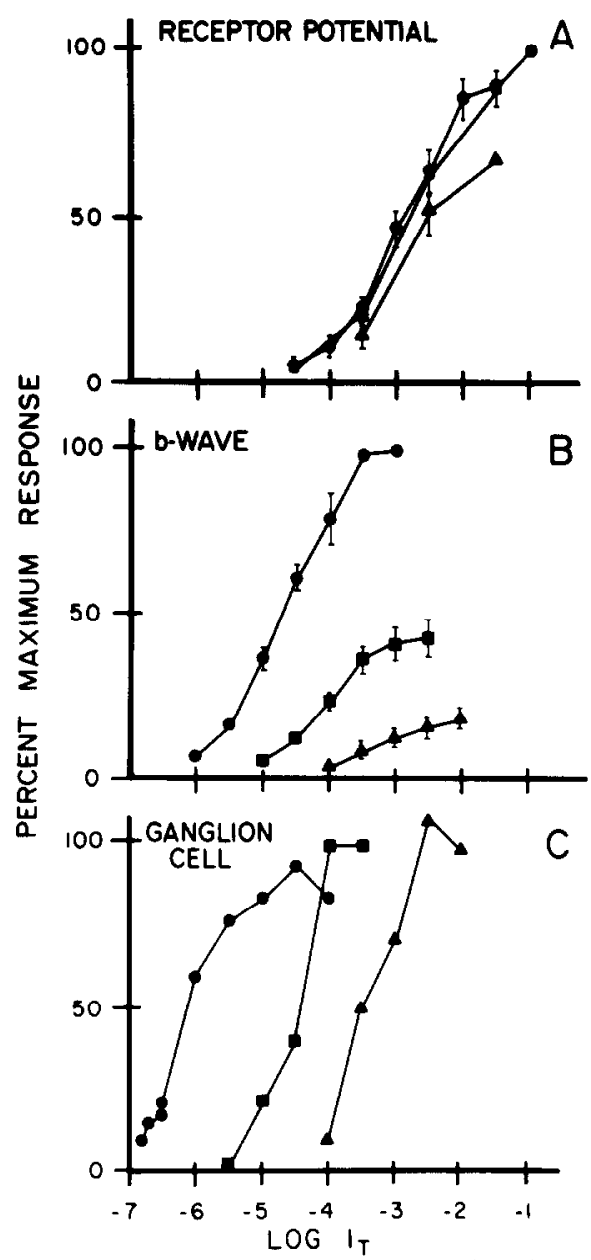

Fig. 3. Comparison of intensity vs response functions across levels of retinal processing. (A) Mean response amplitudes for receptor potential. (B) Mean response amplitudes for $b$-wave. (C) Intensity vs response function for a ganglion cell. (From Green and Powers, 1982.)

move one along the intensity-response curve. That is, if $f(I)$ is the intensity relationship, the presence of a background $I_{\mathrm{B}}$ produces a steady response $f\left(I_{\mathrm{B}}\right)$ upon which the test response rides (Fig. 4). If the curve is compressive (i.e. the slope is a decreasing function of light intensity), then the incremental response will decrease as the background intensity increases. The magnitude of the incremental response is

$$
\Delta R=f\left(I_{\mathrm{B}}+I_{\mathrm{t}}\right)-f\left(I_{\mathrm{B}}\right)
$$

The families of curves in Fig. 5(a-d) show how the incremental response grows if the intensity-response function is of the form proposed by Boynton and Whitten (1970)

$$
R=\frac{I^{\alpha}}{I^{\alpha}+\sigma}
$$

with $\alpha=0.1,0.2,0.5$ and 1.0 in parts (a-d) respectively. The same normalized intensity axis is used as in Fig. 4.

There are a number of interesting and perhaps surprising aspects of these plots. While the shape of the intensity-response curve depends slightly on $\alpha$ [see Fig. 7(a)] except for the responses without a background, all the intensity response curves in each family have roughly the same shape. The $I_{B}=0$ curves are likely to be found experimentally since even in the absence of a real background there will probably be a background of "dark light". Consequently, a single template can be said to adequately fit each family of curves. The effect of any background is to shift the template curve horizontally and vertically on the double log scales. Examination of any one of the sets of curves in Fig. 5 shows that as the background $I_{\mathrm{B}}$ increases it produces horizontal shifts of the template which are proportional to $I_{\mathrm{B}}$. There is also a vertical shift whose magnitude depends on $\alpha$. If one identifies horizontal shifts with changes in "gain", what this means is that, independent of $\alpha$, a system described by equa-

olpho $=0.5$

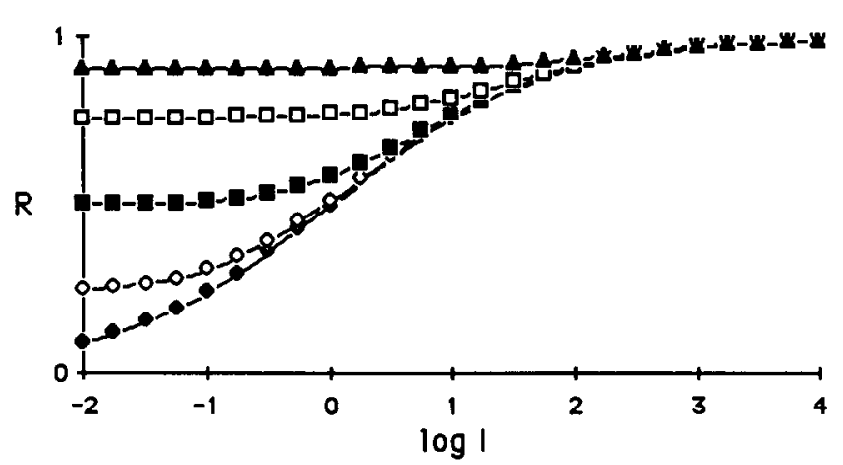

Fig. 4. Resonses produced by a stimulus consisting of variable test and a fixed background for a system defined by equation (2), with $\alpha=0.5$. Each curve is for a different background $\left(I_{B} / \sigma=0,0.1,1,10\right.$ and 100). The vertical axis gives the intensity of the test in normalized units (i.e. $I=I_{\mathrm{t}} / \sigma$ ). 

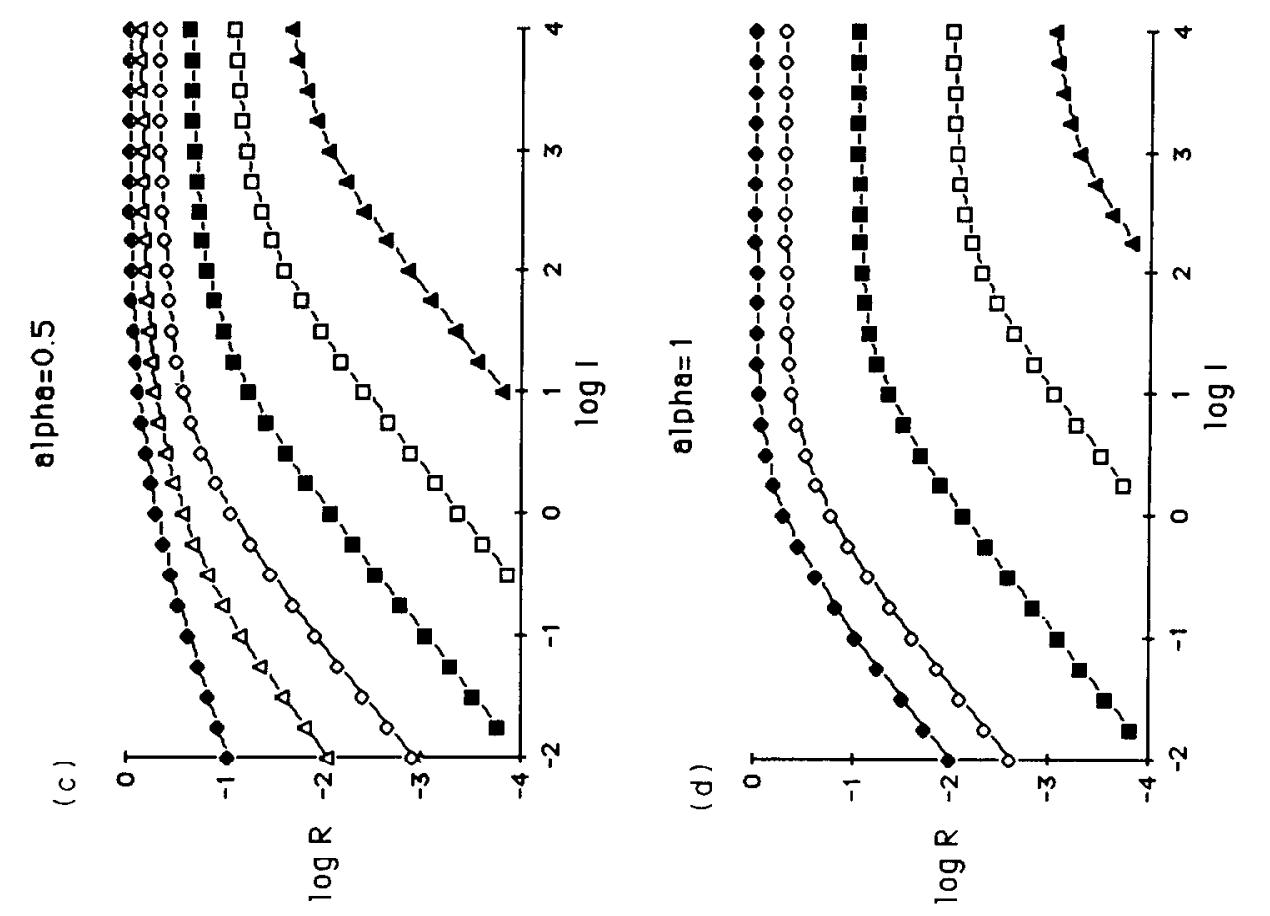

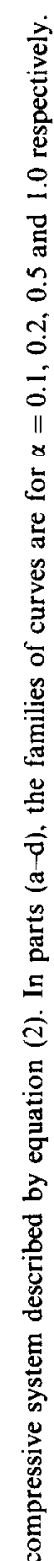
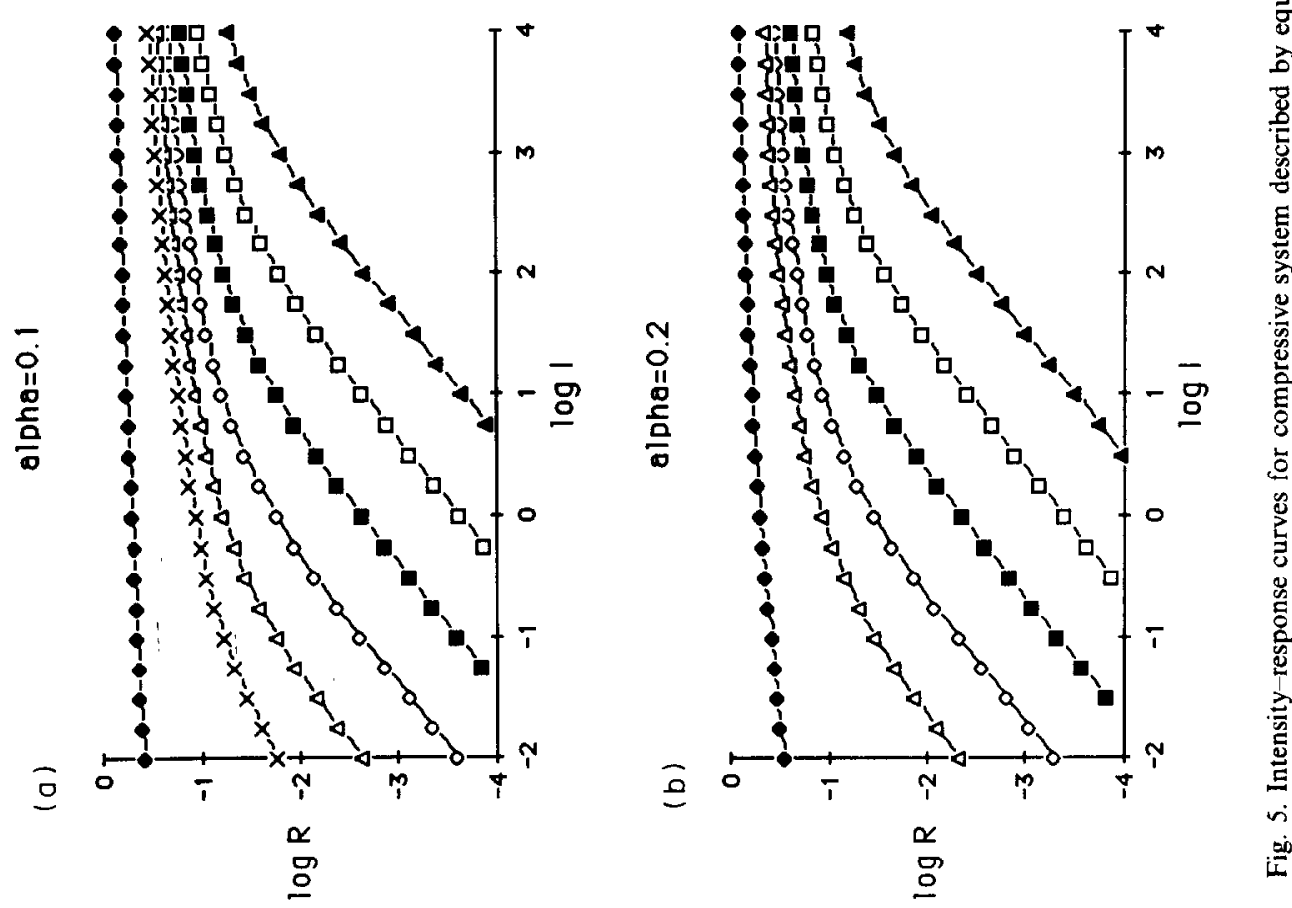


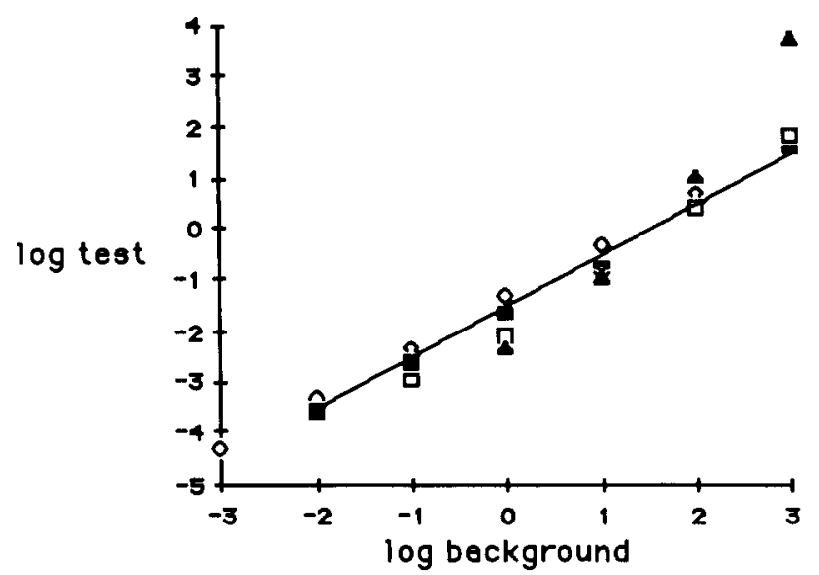

Fig. 6. Increment threshold curves for system defined by equation (1) with the threshold taken to be $\log$ $\Delta R=-3$. The points come from the graphs in Fig. $5(\diamond, \alpha=0.1 ; \square, \alpha=0.2 ; \square, \alpha=0.5$; and $\boldsymbol{\Delta}$, $\alpha=1.0$ ). The smooth line is Weber's law (i.e. $I_{t} / I_{\mathrm{B}}=K$ ).

tion (2) exhibits reductions in "gain" that follow Weber's law! If this seems like an unlikely and surprising result, I must say I agree. The reason this happens is worth examining more carefully.

In the response compression model a given amount of light, whether from test or background, has a fixed effect. In the increment threshold paradigm a background light is fixed at some intensity and a relatively weak test light is added to it. Consequently the effects of the background dominates over that of the test. Only when intensity of the test stimulus begins to approach that of the background will its presence or absence produce a significant change in the total response. It is this requirement that the test be significant relative to the background, that produces the ratio scale. In other words, if the background is increased in intensity by some other factor then the test must also be increased by about the same amount before its effects will again be significant. Thus "Weber's law" is the consequence of two things (1) a model in which light has a single universal effect and (2) the fact that physical addition of two unequal lights results in a stimulus which is not significantly different from the larger of the two.

Time constraints often prevent one from measuring complete sets of intensity-response curves. Consequently, the more common experimental manipulation is to determine a threshold, which is the stimulus intensity required to produce a fixed, but small increment in response. How does threshold vary with background? This can be determined from the graphs in Fig. 5 by drawing a horizontal line at some fixed response level. The intersection of this line with each curve gives the stimulus intensity required to produce the preselected incremental response. Figure 6 shows how increment threshold depends on background intensity for the four values of $\alpha$. When $\alpha=1.0$ threshold increases with background at first are smaller than those predicted by Weber's law and then the threshold response tends to saturate (Williams and Gale, 1977). For $\alpha=0.1$ and 0.2 and 0.5 the curves are rather well fit by Weber's law over a significant range of backgrounds.

Two other relationships are worth considering.

\section{Stimulus scaling}

Probably the simplest adaptational mechanism one can imagine is one where the effect of adaptation is to decrease the potency of the test probe. MacLeod (1978) has called this the "dark glasses" model of adaptation. That is, desensitization produces an effect that is equivalent to reducing the test-stimulus intensity. Pigment depletion would have this effect but this might also occur if, for example, adaptation depleted the store of chemical synaptic transmitter. In both instances a light stimulus presented against a background light will have less effect than in the dark. The amplitude of the response, however, could be restored to its original size by simply increasing the stimulus intensity. In other words, the effect of an adapting stimulus is to cause a lateral shift of the intensity response function along the log intensity axis [Fig. 7(b)]. Formally, stimulus scaling is equivalent to having a response function whose argument can be written as the product of a scaling parameter and stimulus intensity

$$
R=f\left[c\left(I_{\mathrm{B}}\right) \cdot I_{\mathrm{t}}\right] .
$$


(a)

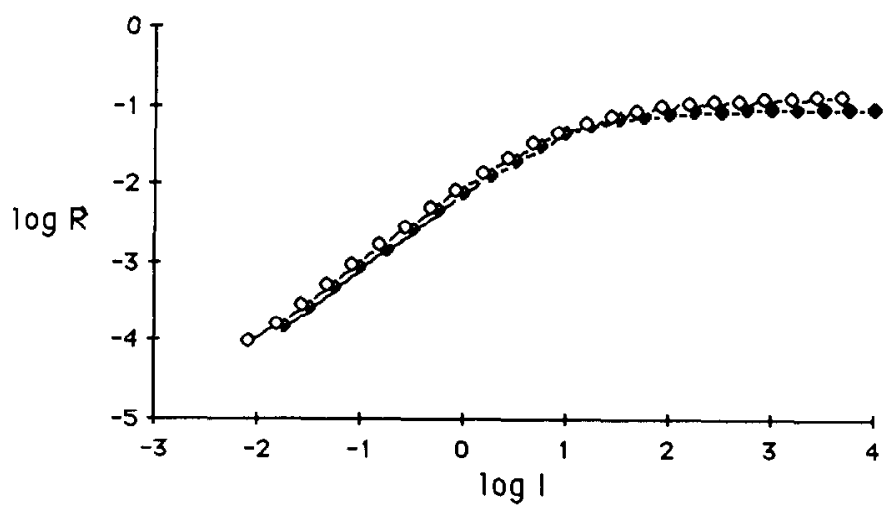

(b)
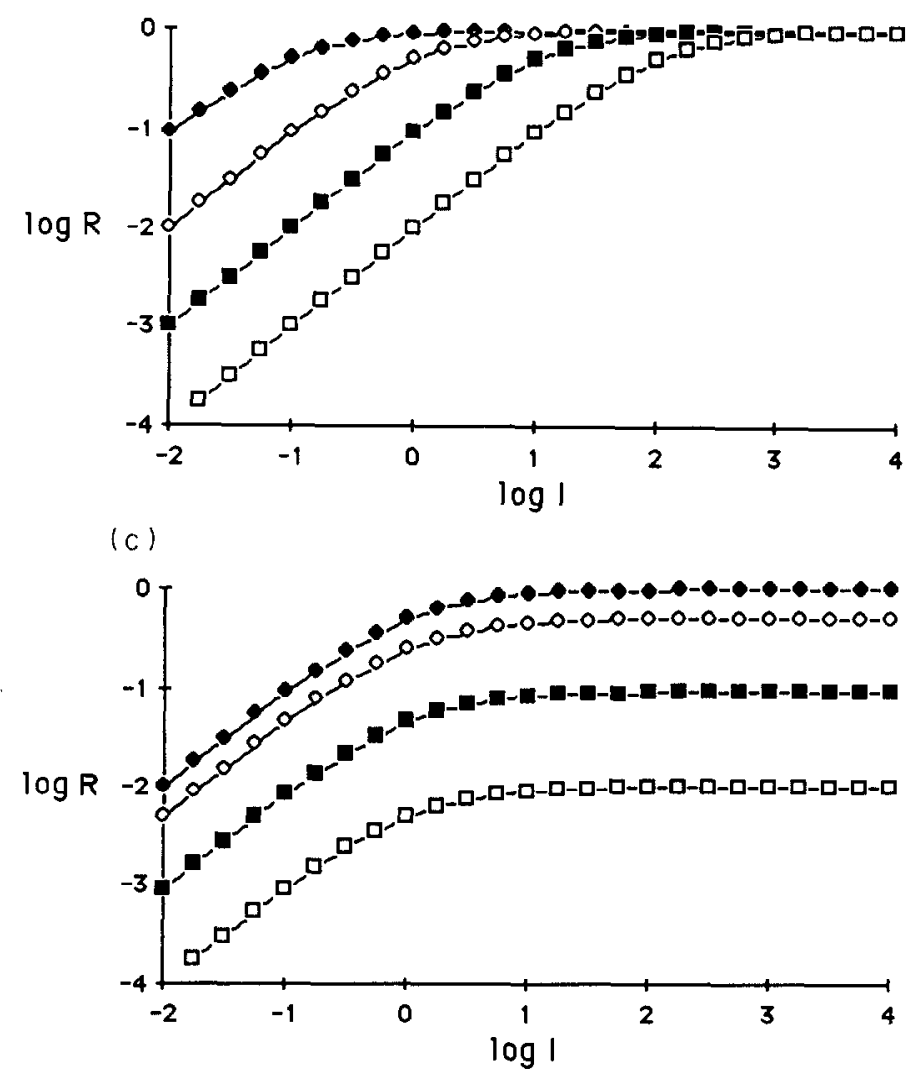

Fig. 7. (a) Comparison of shapes of "template" curves for $\alpha=1.0$ and 0.5 . For each family of curves shown in Fig. 5 there is a single template, but changing $\alpha$ does affect the shape of the template slightly.

(b) $V-\log I$ curves for stimulus scaling. (c) $v-\log I$ curves for response scaling.

The scaling parameter $c\left(I_{\mathrm{B}}\right)$ varies with the background intensity and thus determines the magnitude of shift on the $\log I$ axis. An example of this would be a Michaelis-Menton relationship with a half saturation constant that depends on background intensity

$\frac{V}{V_{\max }}=\frac{I_{\mathrm{t}}}{I_{1}+\sigma\left(I_{\mathrm{B}}\right)}=\frac{I_{\mathrm{t}} / \sigma\left(I_{\mathrm{B}}\right)}{I_{\mathrm{t}} / \sigma\left(I_{\mathrm{B}}\right)+1}=\frac{c\left(I_{\mathrm{B}}\right) I_{\mathrm{t}}}{c\left(I_{\mathrm{B}}\right) I_{\mathrm{t}}+1}$ where

$$
c\left(I_{\mathrm{B}}\right)=\frac{1}{\sigma\left(I_{\mathrm{B}}\right)}
$$

\section{Response scaling}

An equally interesting alternative is response scaling. That is, adaptation can be described by a function which can be separated into the product of two functions, each depending on $I_{\mathrm{B}}$ 
and $I_{1}$ alone

$$
R=g\left(I_{\mathrm{D}}\right) f\left(I_{\mathrm{t}}\right)
$$

Adaptation attenuates the size of the response, without affecting the form of the light dependency. Probably the best known example of this kind of adaptational interaction was proposed by Alpern, Rushton and Torii (1970). That is

$$
R=\frac{\sigma}{\left(I_{\mathrm{B}}+\sigma\right)} \frac{I_{\mathrm{t}}}{\left(I_{\mathrm{t}}+\theta\right)}
$$

On a double log plot of response versus stimulus intensity-response scaling leads to downward shifts of the curves. This is in contrast to stimulus scaling which produces horizontal shifts [see Fig. 7(c)]. Response compression combines both effects and results in shifts of the curves down and to the right. Figure 5 illustrates, for example, that a system described by equation (3), if alpha is less than 0.5 , exhibits predominately horizontal shifts. The magnitude of this shift is roughly proportional to background intensity over a wide range of backgrounds. A compressive system can also produce predominantly vertical shifts. To see this consider an intensity-response function of the form

$$
R=\left(1-\mathrm{e}^{-I}\right)
$$

The incremental response to a stimulus, $I_{t}$, on a steady background, $I$ is given by

$$
\begin{aligned}
R & =1-\mathrm{e}^{-\left(I_{\mathrm{t}}+I_{\mathrm{B}}\right)} \quad-\left(1-\mathrm{e}^{-I_{\mathrm{B}}}\right) \\
& =\mathrm{e}^{-I_{\mathrm{B}}}-\mathrm{e}^{-\left(I_{\mathrm{t}}+I_{\mathrm{B}}\right)} \\
& =\mathrm{e}^{-I_{\mathrm{B}}} \quad\left(1-\mathrm{e}^{-I_{\mathrm{t}}}\right) .
\end{aligned}
$$

Thus the incremental response can be separated into a product of two functions, each dependent on the test or background alone.

\section{Sites of adaptation}

None of the above says very much about where in the retina sensitivity is being regulated. Stimulus scaling has to occur prior to any compressive transformation. This would seem to imply a mechanism that acts at, or before, the first chemical synapse. On the other hand, response scaling and response compression must occur at or beyond the first nonlinear transformation.

Probably the most direct approach to understanding where things happen in the retina is to compare the changes in sensitivity in photoreceptors with those in second order neurons.
Unfortunately this approach has its difficulties. First, there is the one of finding a retina in which all of the neurons can be penetrated and examined for sufficient time to do quantitative studies. Second, there is the problem of comparing the adaptive properties of neurons whose responses have different waveforms and are obtained with different recording techniques. How does one compare the slow graded responses from photoreceptors with the spike discharges from retinal ganglion cells?

The approach that we (Green et al., 1975) took was to use a combination of mass responses and single cell recordings. By comparing the effect that backgrounds have on incremental flash sensitivity and on intensity response curves it was possible to infer where changes occurred. Figure 8 , for example, shows intensity response curves (from Green $e t$ al., 1975) for the aspartate isolated receptor potential, intracellular horizontal cell responses, and $b$-wave, recorded in the skate eyecup. A dim

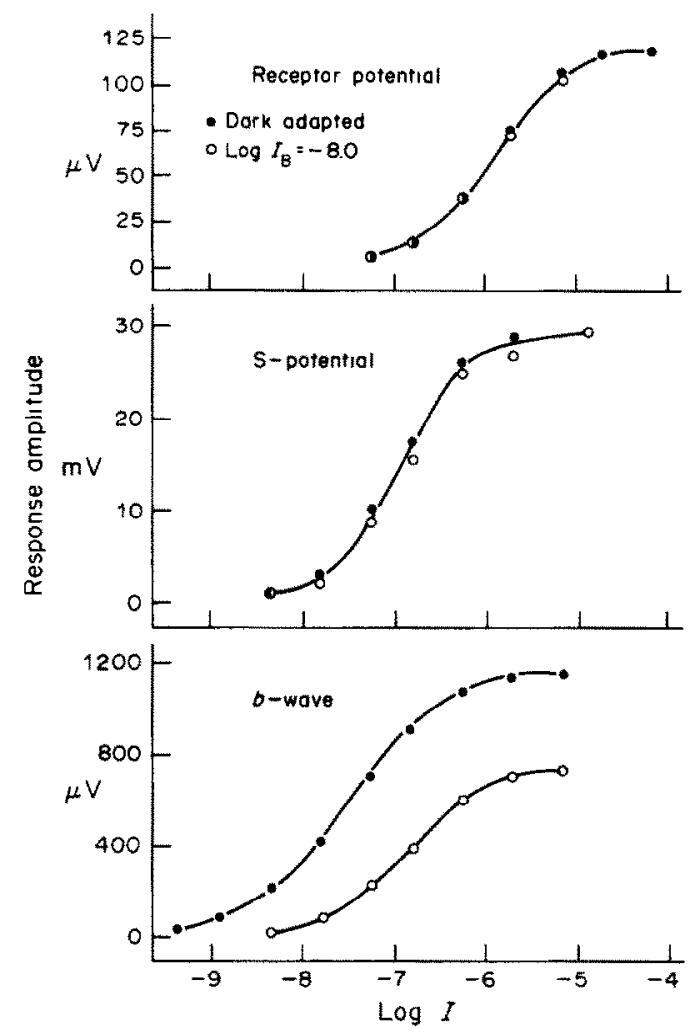

Fig. 8. Intensity-response $(V-\log I)$ curves from skate retina. The receptor potential, intracellular horizontal cell responses (S-potential), and $b$-wave were recorded in the dark and in the presence of a dim adapting field (log $I_{\mathrm{B}}=-8$ ). The $V-\log I$ curve of the $b$-wave is shifted by about $1 \log$ unit to the right by this background field and its maximum amplitude is reduced. However the receptors and horizontal cells are not affected by this level 'of illumination. (From Green et al., 1975.) 


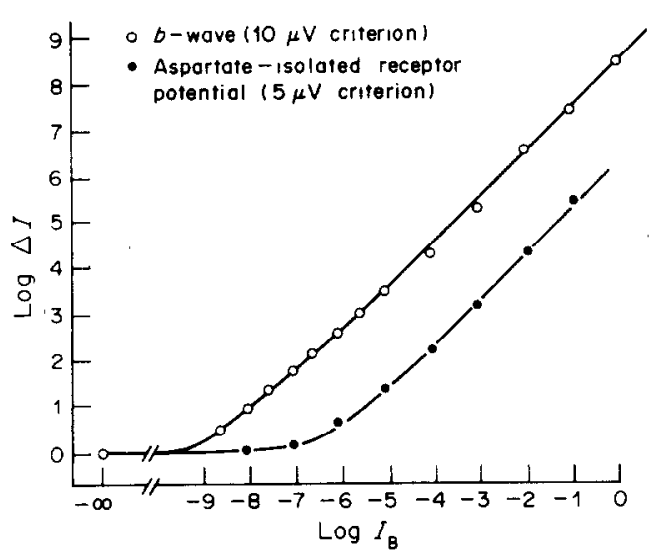

Fig. 9. Increment thresholds for the $b$-wave and isolated receptor potential from skate retina. The absolute thresholds for both responses have been equated at $\log \Delta I=0$. Thresholds were determined $4 \mathrm{~min}$ or more after each increase in $I_{\mathrm{B}}$ to ensure that a stable threshold level had been reached. With dim backgrounds $\left(I_{\mathrm{B}}=-9\right.$ to -7$)$ the $b$ wave threshold is significantly altered but there is no discernible effect on receptor threshold. With brighter backgrounds, the sensitivity of the receptor response is also decreased and both functions rise in parallel with a slope of about one. (From Green et al., 1975.)

background has different effects on the responses measured from different levels in the retina. ERG $b$-wave sensitivity is depressed by a $\log$ background intensity of -8 , which has no significant effect on the receptorial or horizontal cell responses. That is, at low levels a synaptically elicited gain control significantly affects post-receptor neurons but receptors exhibit little or no change in sensitivity (we called this network adaptation). This is not the whole story, however, as is illustrated in Fig. 9 where incremental thresholds for the receptors and the $b$-wave are compared over a wide range of intensities. In contrast to the case above, with a background brighter than $\log I_{\mathrm{B}}=-5$, the threshold of the receptors and the $b$-wave now show similar dependencies on background intensity. Presumably this is because at these higher levels of illumination the receptors themselves adapt, and the $b$-wave threshold simply reflects these receptor changes.

Thus, these experiments indicate two principle mechanisms regulate changes in sensitivity in skate-one in the receptors and the other in the network of post-receptor neurons. Both of these seemed to make good sense. Light adaptation serves to rescale neural responses so that the eye can function over a wide dynamic range. Close to absolute threshold, the shower of photons falling on the retina is so sparse that photoreceptors only occasionally absorb a pho- ton. Receptors have no need to adapt. This is not necessarily the case at second order neurons. A combination of convergence of many signals and high gain at the rod to bipolar synapse could produce post-receptor signals of sufficient size to require that neurons adjust their gain. Changes in the properties of these post-receptor cells in the retinal network would then be the basis for the adaptation pool.

Several sites of adaptation, each coming into play under the appropriate circumstances would seem to be a good design. Every cell in the retina might in fact be capable of modifying its response range (Normann and Werblin, 1974; Werblin, 1974; Werblin and Copenhagen, 1974). This insight, at the time, was exciting and important. It raised a number of significant new questions and provided a framework in which the old but unresolved questions about adaptive mechanisms might be addressed. How, for example, does one apply the notion that several kinds of retinal neuron can adapt to a duplex retina? Does each photoreceptor system function independently with each exhibiting both receptor and network adaptation? There are a whole range of "how" and "where" questions such as, "How and where does bleaching a small amount of visual pigment produce a profound and persistent loss of sensitivity?"

Unfortunately, one thing had been overlooked. The distinction between receptor and network adaptation in good part derives from an over-simplified view of retinal circuitry. Implicit in much of our thinking was the notion that each photoreceptor functioned independently. That is, we assumed that a photoreceptor's response was dependent only on the light it absorbed in its outer segment. At least for cold blooded vertebrate retinas this was wrong (Baylor et al., 1971; Baylor and Hodgkin, 1973; Fain, 1976; Schwartz, 1975; Copenhagen and Owen, 1976). Photoreceptors in some retinas are synaptically coupled through sign conserving synapses to their near neighbors, and through sign inverting synapses to their more distant neighbors. The basis for the synergistic effects are electrical connections between photoreceptors (Copenhagen and Owen, 1980; Detweiler and Hodgkin, 1979) and possibly chemical ones (Normann et al., 1984); the basis for the antagonistic effects is the horizontal cell feedback onto photoreceptors. Thus, rather than functioning independently, each photoreceptor is an integral part of an elaborate synaptic network. 
(A)

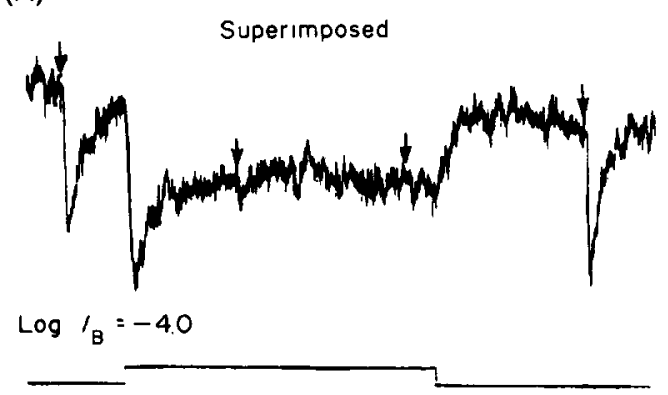

(B)

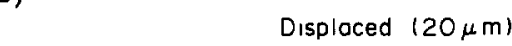

(C)
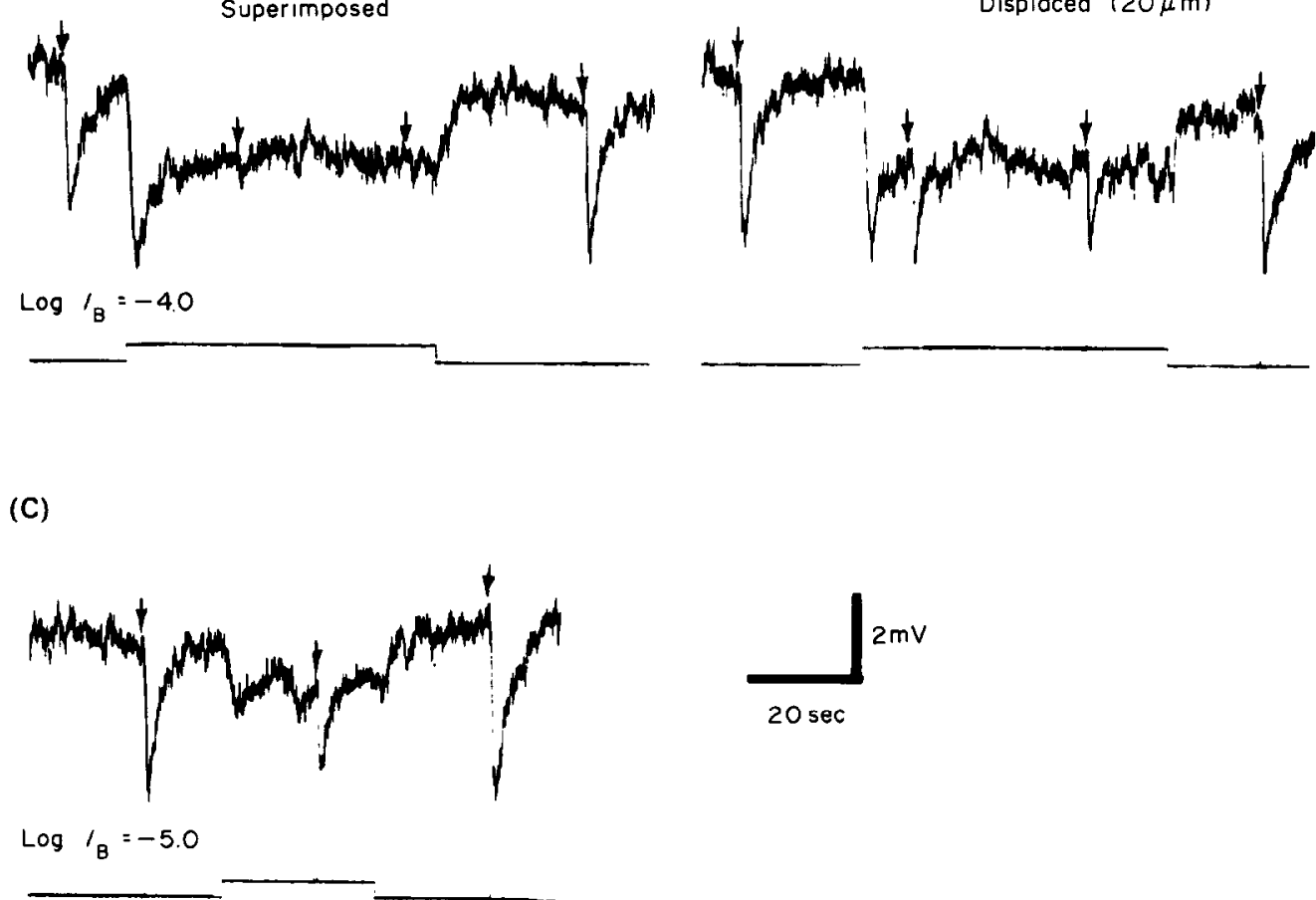

Fig. 10. Failure to find spread of adaptation through coupled rod network in snapping turtle retina. Effects of superimposed and displaced slits on intracellular responses from rod photoreceptors. All flash responses are to a $25 \mu \mathrm{m}$ diameter spot centered on the impaled rod. (A) Initial control test response is followed by superimposed adapting slit $(\log I=-4.0,510 \mathrm{~nm})$ during which 2 test responses are observed. After termination of the slit, another control test spot was flashed. (B) Same protocol as (A) except the slit was displaced $20 \mu \mathrm{m}$ from the centered position. (C) Same protocol as (A) except centered slit intensity was reduced by $1 \log$ unit $\left(\log I_{\mathrm{B}}=-5.0\right)$ to equate the adapting effect with that shown in (B). (From Copenhagen and Green, 1985.)

Given the above, it becomes necessary to know the extent to which signals spreading from one receptor to another can modify sensitivity. David Copenhagen and I have recently published the results of our experiments designed to answer this question for the rods of the snapping turtle (Copenhagen and Green, 1985). The first experiments we tried were stimulated by Rushton's finding that it took very few photons to significantly elevate thresholds in man (Rushton, 1965b). From this Rushton argued that the rods that saw the background must somehow raise the threshold of the ones that did not. What we found was that a background so dim that each rod absorbed a photon only once every $10 \mathrm{sec}$ could halve the flash sensitivity of the intracellularly recorded snapping turtle rod response. This seemed much like the Rushton result and suggested pooling of adaptation. However, detailed measurements of the spatial spread of adaptation failed to show pooling over distances greater than could be accounted for by stray light. Figure 10 shows sample records from these experiments. An adapting slit superimposed on a small test spot has a much larger desensitizing effect than when it is moved $20 \mu \mathrm{m}$ away. This is true in spite of the fact that the hyperpolarizing responses evoked by the slit under the two conditions are virtually identical.

Having obtained these results, we realized we needed to rethink our original conclusions. What we had glossed over is the fact that the logic of inferring pooling involves an implicit assumption about how long the effect of each photoisomerization persists. That is, if one finds, as we did, that 0.1 photon absorbed per rod per sec can adapt, before concluding there is pooling one needs to exclude the possibility that a single photoisomerization produces a massive desensitizing effect which persists for $10 \mathrm{sec}$ or more. Rather than eliminating this 
possibility, our experiments suggest that this is exactly what happens. These experiments imply that the effect of a single photon absorption spreads longitudinally along the length of the outer segment and desensitizes the whole photoreceptor. It surely would be nice to know how this is done!

It seems particularly strange to be advocating an idea that William Rushton was so soundly demolishing 25 years ago when I entered the field. Wald's compartment hypothesis required that the absorption of a single photon could inactivate all the rhodopsin in a disk. While this always seemed a bit far-fetched, I now find myself led to conclude that a photon can have an even more devastating effect-not one but many disks are affected.

As contradictory as it may seem, I still believe Rushton was essentially correct. This may be no more than an ability to give up old ideas, but I think not. One should not forget about species differences. There is ample evidence that rods in different animals can adapt differently. While there may be biological pressures tending to drive animals toward the same levels of performance this does not necessarily eliminate the possibility for differences in the details of how it is done. In man and other mammals I suspect that the rods themselves do not adapt (Rushton, 1965a; Dowling, 1967; Enroth-Cugell and Shapley, 1973; Green, 1973; Green and Powers, 1982; Baylor et al., 1984). On the other hand, preliminary measurements comparing snapping turtle rods and ganglion cells suggest that in the retina the changes in the photoreceptors account for all or most of the changes in retinal sensitivity (Green, unpublished).

Finally, it is a bit dismaying to realize we are still debating many of the same issues we were 25 years ago, yet I firmly believe we are making real progress. This suggests to me that we can look forward with some optimism to where we will be 25 years hence. I for one am counting on being able to understand the synaptic and chemical machinery that produces visual adaptation in much better detail than is possible today.*

\footnotetext{
* In retrospect, it is easy to see how poorly I have understood the past and how badly I have predicted the future. The latter is understandable and the former should be unforgivable. Yet I know I have slighted many who have made substantial contributions. Please accept my apologies and treat this as a very personal account of one person's search for the site(s) of visual adaptation.
}

Acknowledgements - I am grateful to Marilyn Glover for technical assistance in the preparation of the manuscript and illustrations. This work was assisted by NIH Grant EY 00379

\section{REFERENCES}

Adelson E. (1982) Saturation and adaptation in the rod system. Vision Res. 22, 1299-1312.

Alpern M., Rushton W. A. H. and Torii S. (1970) The attenuation of rod signals by backgrounds. J. Physiol., Lond. 206, 209-277.

Barlow H. B. and Andrews D. P. (1967) Sensitivity of receptors and receptor 'pools'. J. opt. Soc. Am. 57, 837-838.

Baylor D. A., Fuortes M. G. F. and O'Bryan P. M. (1971) Receptive fields of cones in the retina of the turtle. $J$. Physiol., Lond. 214, 265-194.

Baylor D. A. and Hodgkin A. L. (1973) Detection and resolution of visual stimuli by turtle photoreceptors. $J$. Physiol., Lond. 234, 163-198.

Baylor D. A. and Hodgkin A. L. (1974) Changes in time scale and sensitivity in turtle photoreceptors. J. Physiol., Lond. 242, 729-758.

Baylor D. A., Nunn B. J. and Schnapf J. L. (1984) The photocurrent, noise and spectral sensitivity of rods of the monkey. J. Physiol., Lond. 357, 575-607.

Boynton R. M. and Whitten D. N. (1970) Visual adaptation in monkey cones: recording of late receptor potentials. Science, N.Y. 170, 1423-1426.

Campbell F. W. and Rushton W. A. H. (1955) Measurement of scotopic pigments in the living human eye. J. Physiol., Land. 130, 131-147.

Cicerone C. M. and Green D. G. (1980) Dark adaptation within the receptive field centre of rat retinal ganglion cells. J. Physiol, Lond. 301, 535-548.

Cleland B. G. and Enroth-Cugell C. (1968) Quantitative aspects of sensitivity and summation in the cat retina. J. Physiol., Lond. 198, 17-38.

Copenhagen D. R. and Green D. G. (1985) The absence of spread of adaptation between rod photoreceptors in turtle retina. J. Physiol., Lond. 369, 161-182.

Copenhagen D. R. and Owen W. G. (1976) Functional characteristics of lateral interactions between rods in the retina of the snapping turtle. J. Physiol., Lond. 259, 251-282.

Copenhagen D. R. and Owen W. G. (1980) Currentvoltage relations in the rod photoreceptor network of the turtle retina. J. Physiol., Lond. 308, 159-184.

Detweiler P. B. and Hodgkin A. L. (1979) Electrical coupling between cones in turtle retina. J. Physiol., Lond. 291, 75-100.

Dowling J. E. (1967) The site of visual adaptation. Science, N.Y. 155, 273-278.

Dowling J. E. and Ripps H. (1970) Visual adaptation in the retina of the skate. J. gen. Physiol. 56, 491-520.

Dowling J. E. and Ripps H. (1971) S-potentials in the skate retina: Intracellular recordings during light and dark adaptation. J. gen. Physiol. 58, 163-189.

Dowling J. E. and Ripps H. (1972) Adaptation in skate photoreceptors. J. gen. Physiol. 60, 698-719.

Easter S. S. (1968) Adaptation in goldfish retina. $J$. Physiol., Lond. 195, 273-281.

Enroth-Cugell C. and Shapley R. M. (1973) Flux, not retinal illumination, is what cat retinal ganglion cells really care about. J. Physiol., Lond. 233, 311-326. 
Fain G. L. (1976) Sensitivity of toad rods: dependence on wave-length and background illumination. J. Physiol., Lond. 261, 71-101.

Grabowski S. R., Pinto L. H. and Pak W. L. (1972) Adaptation in retinal rods of axolotl: intracellular recordings. Science, N.Y. 176, 1240-1242.

Granit R., Holmgren T. and Zewi M. (1938) On the mode of action of visual purple on the rod cell. J. Physiol., Lond. 88, 436-458.

Granit R., Munsterhjelm A. and Zewi M. (1939) The relationship between concentration of visual purple and retinal sensitivity to light during dark adaptation. $J$ Physiol., Lond. 96, 31-44.

Green D. G. (1973) Scotopic and photopic components of the rat electroretinogram. J. Physiol., Lond. 228, 781-797.

Green D. G., Dowling J. E., Siegel I. M. and Ripps H. (1975) Retinal mechanisms of visual adaptation in the skate. J. gen. Physiol. 65, 483-502.

Green D. G., Tong L. and Cicerone C. M. (1977) Lateral spread of light adaptation in the rat retina. Vision Res. 17, 497-486.

Green D. G. and Powers M. K. (1982) Mechanisms of light adaptation in rat retina. Vision Res. 22, 209-216.

Hecht S. (1924) The visual discrimination of intensity and the Weber-Fechner Law. J. gen. Physiol. 7, 235-267.

Hecht S. (1934) The nature of the photoreceptor process. Handbook of General Experimental Psychology (Edited by Murchison C.).

Hood D. C. and Hock P. A. (1973) Recovery of cone receptor potential activity in the frog's isolated retina. Vision Res. 13, 1943-1951.

Kleinschmidt J. and Dowling J. E. (1975) Intracellular recordings from Gecko photoreceptors during light and dark adaptation. J. gen. Physiol. 66, 617-648.

Lipetz L. E. (1961) A mechanism of light adaptation. Science, N.Y. 133, 939-640.

Lythgoe R. J. (1940) The mechanism of dark adaptation: a critical resume. Br. J. Opthal. 24, 21-43.

MacLeod D. I. A. (1978) Visual sensitivity. Ann. Rev. Psychol. 29, 613-645.

Normann R. A. and Werblin F. S. (1974) Control of retinal sensitivity. 1. Light and dark adaptation of vertebrate rods and cones. J. gen. Physiol. 63, 37-61.

Normann R. A., Perlman I., Kolb H., Jones J. and Daly S. J. (1984) Direct excitatory interactions between cones of different spectral types in turtle retina. Science, N.Y. 224, 625-627.

Rushton W. A. H. (196la) The intensity factor in vision In Light and Life (Edited by McElroy W. D. and Gloso B.), pp. 706-722, Johns Hopkins Press, Baltimore, Md.

Rushton W. A. H. (1961 b) Rhodopsin measurement and dark-adaptation in a subject deficient in cone vision. $J$ Physiol., Lond. 156, 193-205.

Rushton W. A. H. (1965a) Visual adaptation (The Ferrier Lecture). Proc. R. Soc. B. 162, 20-46.

Rushton W. A. H. (1965b) The sensitivity of rods under illumination. J. Physiol, Lond. 178, 141-160.

Rushton W. A. H. and Westheimer G. (1962) The effect upon rod threshold of bleaching neighboring rods. $J$. Physiol., Lond. 164, 318-329.

Schouten J. F. and Ornstein L. S. (1939) Measurements on direct and indirect adaptation by means of a binocular method. J. opt. Soc. Am. 29, 168-182.

Schwartz E. A. (1975) Rod-rod interaction in the retina of the turtle. J. Physiol., Lond. 246, 617-638.

Shapley R. and Enroth-Cugell C. (1983) Visual adaptation and retinal gain controls. Prog. Retinal Res. 3, 263346.

Tong L. and Green D. G. (1977) Adaptation pools and excitation receptive fields of rat retinal ganglion cells. Vision Res. 17, 1233-1236.

Wald G. (1954) On the mechanism of the visual threshold and visual adaptation. Science, N.Y. 119, 887-892.

Werblin F. S. (1974) Control of retinal sensitivity. II. Lateral interactions at the outer plexiform layer. J. gen. Physiol. 63, 62-87.

Werblin F. S. and Copenhagen D. R. (1974) Control of retinal sensitivity. III. Lateral interactions at the inner plexiform layer. J. gen. Physiol. 63, 88-110.

Williams T. P. and Gale J. G. (1977) A critique of an incremental threshold function. Vision Res. 17, 881-882.

Witkovsky P., Nelson R. and Ripps H. (1973) Action spectra and adaptation properties of carp photoreceptors. J. gen. Physiol. 71, 401-423. 